\title{
Genetic Variability in Glucosinolates in Seed of Brassica juncea: Interest in Mustard Condiment
}

\author{
Othmane Merah ${ }^{1,2,3}$ \\ ${ }^{1}$ Département Environnement et Agronomie, ENESAD, 26 Boulevard Docteur Petitjean, BP 87999, 21079 Dijon, France \\ ${ }^{2}$ Laboratoire de Chimie Agro-Industrielle (LCA), INP-ENSIACET, Université Fédérale de Toulouse-Midi-Pyrénées, \\ 118 Route de Narbonne, 31030 Toulouse Cedex 4, France \\ ${ }^{3}$ Laboratoire de Chimie Agro-Industrielle (LCA), INRA, 31030 Toulouse, France
}

Correspondence should be addressed to Othmane Merah; othmane.merah@ensiacet.fr

Received 11 March 2015; Revised 3 June 2015; Accepted 4 June 2015

Academic Editor: Patricia Valentao

Copyright (C) 2015 Othmane Merah. This is an open access article distributed under the Creative Commons Attribution License, which permits unrestricted use, distribution, and reproduction in any medium, provided the original work is properly cited.

\begin{abstract}
Brassica juncea is mostly used for oil production which implies selection of genotypes with low glucosinolates level and high oil content. In contrast, condiment production needs varieties with high level in some glucosinolates including sinigrin. The genetic variability was studied mostly by molecular tools. The objectives were almost the decrease of glucosinolates level in order to use the oilcake for animal feed. The aim of this work is to study the genetic variability for different glucosinolates and their relationships with agronomical traits within a large collection of Brassica juncea genotypes for condiment uses. A collection of 190 genotypes from different origins was studied in Dijon (France). Oil content and total glucosinolates, and sinigrin and gluconapin levels were measured. Flowering and maturation durations, seed yield, and yield components were also measured. Large variability was observed between genotypes for the measured traits within the studied collection. Total glucosinolates varied twofold between extreme genotypes. Values of sinigrin content varied from 0 to more than $134 \mu \mathrm{mol} \cdot \mathrm{g}^{-1}$. Correlations between glucosinolates traits and both phenological and agronomical characters are presented and discussed for their potential for industrial condiment uses.
\end{abstract}

\section{Introduction}

Several studies have demonstrated the influence of nutritional factors on the risk of developing cancer. Diet composition is one of the numerous factors that can act to increase cancer prevention. It acts both as a risk factor (food consumed in excess promotes the development of cancer) and protection (nutrients or foods known for their protective effect against cancers). A number of studies support that Brassicaceae species present chemoprevention against cancer forms in humans due to the high levels of glucosinolates [1-4]. The hydrolysis of glucosinolate generates volatile compounds such as isothiocyanates, epithionitriles, and nitriles. These molecules are produced when myrosinase (thioglucosidase) cleaves the thioglycoside linkage of glucosinolates. At neutral $\mathrm{pH}$, the hydrolysis of glucosinolates results in production of isothiocyanates and nitriles, whereas epithionitriles are formed in the presence of ferrous ions and epithiospecifier proteins $[5,6]$. Recent studies have reported that other proteins (including PEN2, family 1 glycosyl hydrolase) may catalyze the hydrolysis of glucosinolates [7-9].

Cruciferous plants are edible as vegetables or as oil. Brown mustard (Brassica juncea L. Czern.) is one of the three oilseed Brassica species. As it is the case in India and China, the brown mustard is used for oil production which involved breeding varieties with low glucosinolates and low erucic acid levels in grains [10]. No information is available concerning the study of glucosinolate content for industrial condiment production. Indeed, in Burgundy (east of France), mustard is used for the production of the condiment "Moutarde de Dijon." In this case, some glucosinolates including gluconapin (GNA, 3-butenyl Gls) must be present at a low level, but conversely high sinigrin (SIN, 2-propenyl Gls) content is required for its hot taste. Following seeds crush in the presence of water, sinigrin undergoes hydrolysis by a myrosinase release allyl isothiocyanate, which is a volatile compound responsible for the flavour of the mustard condiment. 
TABLE 1: Weather conditions recorded from March to August in 2002 and the mean of twenty last years in Dijon (east of France).

\begin{tabular}{lcc}
\hline Weather conditions & 20 years & 2002 \\
\hline Rainfall $(\mathrm{R}, \mathrm{mm})$ & 322.9 & 71.2 \\
Evapotranspiration $(\mathrm{ET}, \mathrm{mm})$ & 455.7 & 246.0 \\
$\mathrm{R} / \mathrm{ET}$ & 0.80 & 0.29 \\
Temperature $\left({ }^{\circ} \mathrm{C}\right)$ & 14.3 & 14.9 \\
\hline
\end{tabular}

Studies of glucosinolate content have concerned rapeseed (by lowering it), broccoli, rocket and Diplotaxis green parts (for cancer prevention and nutritional values), brown mustard for allelopathic activities, and green manure [11-13].

Breeders need large variability to initiate selection programs. Therefore, study of genetic diversity of glucosinolates in large brown mustard collection would help breeders in genitors screening in order to achieve high sinigrin level improvement. However, the majority of works done were performed to decrease glucosinolates [14-16] and erucic acid or to raise seed oil content $[17,18]$. Other studies used molecular markers to structure genetic diversity $[16,17]$. Nevertheless, these reports did not help breeders in genotypes choice in order to perform crosses to manage the glucosinolates level in seed. The few studies which focussed on glucosinolates evaluation were done on few genotypes or performed on green tissues or both [11-13]. However, breeders need to know the genetic diversity of glucosinolates for screening genitors.

Therefore, this study aims to evaluate variability of glucosinolates in seeds within a large collection of genotypes for use in mustard condiment and to investigate relationships between them and agronomical traits.

\section{Materials and Methods}

2.1. Plant Material and Crop Management. A collection of 190 genotypes from different geographic origins were used in this study.

Genotypes were cultivated under rainfed conditions, in the experimental field of ENESA (Etablissement National d'Enseignement Supérieur Agronomique) of Dijon (northeast of France, $47^{\circ} 19^{\prime} \mathrm{N}$ and $5^{\circ} 1^{\prime} \mathrm{E}$ ) during spring season of 2002. A randomized complete block, with two replicates per genotype design, was used for the evaluation of the collection. Seeds were sown in two $5 \mathrm{~m}$ rows per plot $(70 \mathrm{~cm}$ spacing row and $5 \mathrm{~cm}$ interplant spacing). Intergenotypes spacing was $90 \mathrm{~cm}$. The sowing was done at $17 \mathrm{March} 2002$. Harvest took place from 18 to 21 August.

2.2. Weather Conditions. Rainfall, temperature, and evapotranspiration were obtained from meteorological station localised on the INRA experimental field at Dijon. Cumulative rainfalls during the cropping season (March to August) were more than four times lower than mean value of rainfall recorded in the last twenty years for this region (Table 1). However, the precipitations were unequally distributed. Indeed, nearly $72 \%$ of the rainfalls occur during the last three months of the growing cycle. This increase of precipitations was accompanied with an increase of temperatures which in turn raises the evaporative demand at the end of the plant cycle.

2.3. Traits Measurements. In order to determine flowering and mutation durations, dates of beginning and end of flowering as well as maturation were noted. The dates of beginning (DBF) and end (DEF) of flowering were noted when $10 \%$ and $90 \%$ of plants in each plot flowered. The date of maturation (DM) was noted when seeds reached a humidity of $9 \%$. The durations of flowering and maturation were calculated as

$$
\begin{aligned}
\text { flowering duration }(\mathrm{FD}) & =\mathrm{DEF}-\mathrm{DBF}, \\
\text { seed filling duration }(\mathrm{SFD}) & =\mathrm{DM}-\mathrm{DEF} .
\end{aligned}
$$

At the end of flowering, plant height (in $\mathrm{cm}$ ) was measured and the number of plants by row and the number of siliques by row were counted.

At maturity, the number of pods by plant was determined. The plants were harvested by plot and seeds weighed to determine seed yield by plot. Seed yield by plant (SY/P) was then calculated by dividing by the number of plants by plot. Thousand seeds' weight (TSW) was also determined by weighing three samples of thousand seeds for each genotype in each plot.

Sinigrin (SIN), gluconapin (GNA), and total glucosinolates (GSL) contents in the seed were directly determined by HPLC (ISO 9167-1 method) on samples of $50 \mathrm{~g}$ seeds. Content of glucosinolates was expressed in $\mu \mathrm{mol} / \mathrm{g}$ of seed.

2.4. Statistical Analyses. All data were subjected to analysis of variance using GLM procedure of SAS. Association between measured traits was examined using the CORR procedure of SAS.

\section{Results}

The analysis of variance showed large genotypic variability for the measured traits (Table 2). The mean value of total glucosinolates within the studied collection was more than $103 \mu \mathrm{mol} \cdot \mathrm{g}^{-1}$. The difference between extreme genotypes for this trait was twofold (Figure 1). The most important component of these glucosinolates was SIN which varied from 0 to $134.2 \mu \mathrm{mol} \cdot \mathrm{g}^{-1}$. The gluconapin level presented a less large range of variation than for SIN (Figure 1). The mean value of SIN was nearly three times higher than that of GNA. Oil content increased by more than $16 \%$ between extreme genotypes. Three groups of genotypes can be distinguished. The first one is composed of 58 genotypes containing low SIN (less than $30 \%$ of total GLS) and high GNA. One hundred twenty four genotypes composed the second group and are characterized by high level of SIN. Eight other genotypes constitute a third group with an intermediate level of SIN ranged from 35 to $65 \%$ of total GLS.

Large genotypic differences were also observed for the flowering duration (FD) and the seed filling duration (SFD) within the collection (Table 2). Twelve days' difference for FD was observed between extreme genotypes. These differences were more marked for SFD since some genotypes took nearly 
TABLE 2: Mean, standard deviation, and minimal and maximal values of seed glucosinolates compositions as well as agronomical traits measured on a collection of 190 genotypes. Genotypic effect for each trait is also displayed.

\begin{tabular}{|c|c|c|c|c|c|}
\hline Trait & Mean & Standard deviation & Minimum & Maximum & Genotype effect \\
\hline Flowering duration (FD, days) & 25.0 & 2.2 & 21.0 & 33.0 & $* * *$ \\
\hline Seed filling duration (SFD, days) & 46.7 & 5.0 & 35.0 & 63.0 & $* * *$ \\
\hline Plant height $(\mathrm{cm})$ & 176.5 & 26.0 & 105.0 & 230.0 & $* * *$ \\
\hline Number of seeds/pod & 14.4 & 2.7 & 3.1 & 20.4 & $* *$ \\
\hline Thousand seeds' weight (TSW, g) & 3.2 & 0.9 & 1.6 & 7.3 & $* * *$ \\
\hline Seed yield/plant (SY/P, g) & 10.5 & 2.6 & 3.1 & 17.8 & $* * *$ \\
\hline Seed total glucosinolates content (GLS, $\mu \mathrm{mol} \cdot \mathrm{g}^{-1}$ ) & 103.3 & 14.2 & 68.0 & 153.0 & $* * *$ \\
\hline Seed sinigrin content $\left(\mathrm{SIN}, \mu \mathrm{mol} \cdot \mathrm{g}^{-1}\right)$ & 73.0 & 35.4 & 0.0 & 134.2 & $* * *$ \\
\hline Seed gluconapin content $\left(\mathrm{GNA}, \mu \mathrm{mol} \cdot \mathrm{g}^{-1}\right)$ & 27.0 & 37.4 & 0.0 & 106.3 & - \\
\hline Oil content $(\% \mathrm{DM})$ & 41.3 & 3.4 & 31.0 & 47.4 & $* * *$ \\
\hline
\end{tabular}

$* *$ and $* * *$ : significance at 0.01 and 0.001 probability level, respectively.

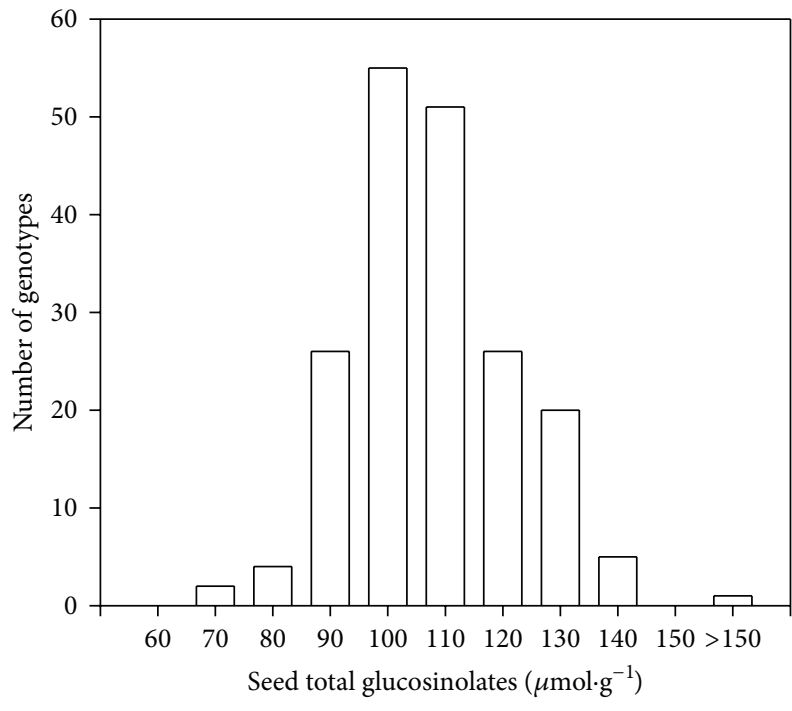

(a)

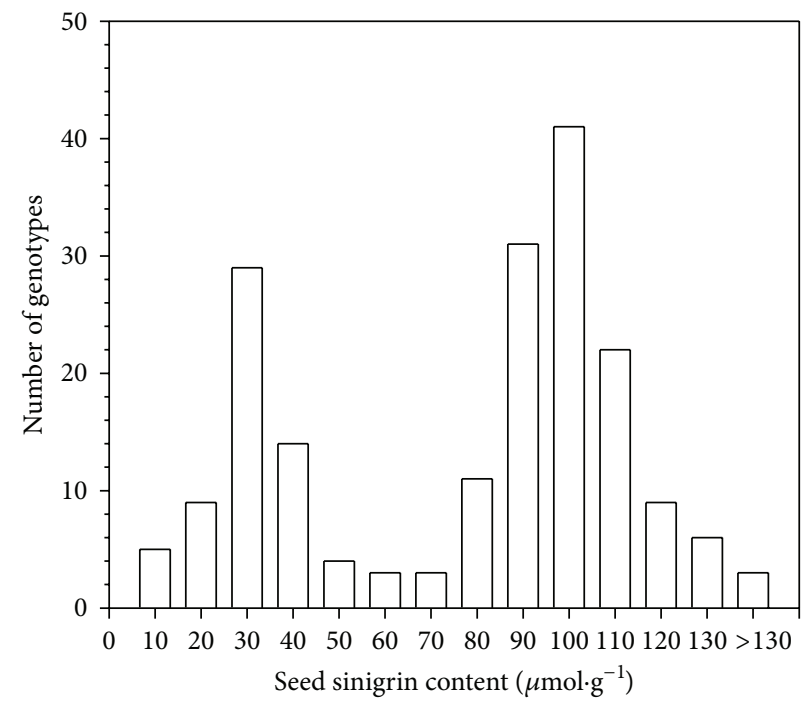

(b)

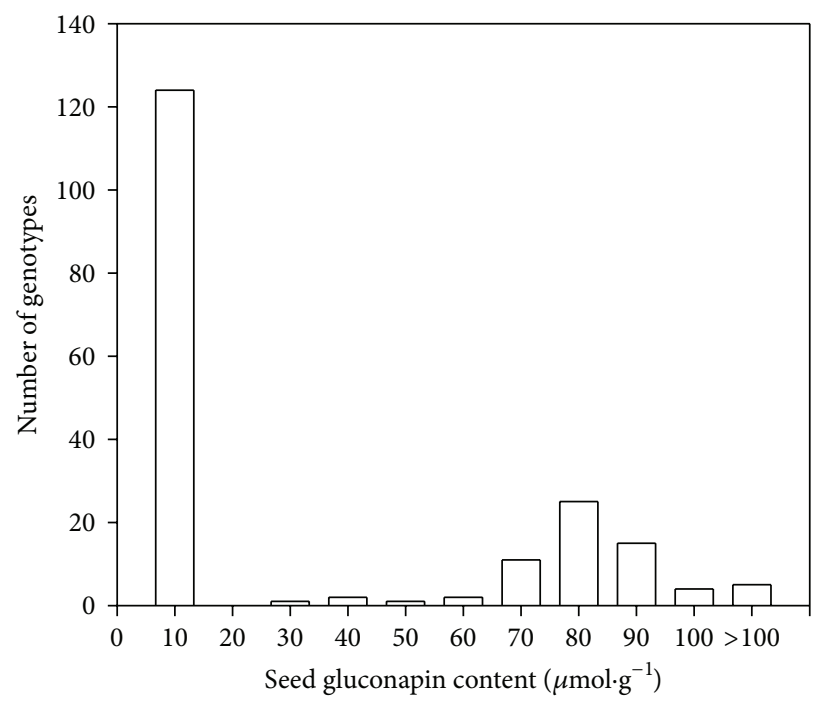

(c)

FIGURE 1: Distribution of seed total glucosinolates, sinigrin, and gluconapin values assessed on a collection of 190 genotypes. 
TABLE 3: Correlations between seed total glucosinolates, sinigrin, and gluconapin and agronomical traits measured on a collection of 190 genotypes.

\begin{tabular}{|c|c|c|c|}
\hline Trait & Seed total glucosinolates & Seed sinigrin content & Seed gluconapin content \\
\hline Flowering duration (FD) & 0.07 & 0.01 & 0.02 \\
\hline Seed filling duration (SFD) & $0.32^{* * *}$ & $-0.55^{* * *}$ & $0.65^{* * *}$ \\
\hline Plant height & -0.04 & $0.73^{* * *}$ & $-0.71^{* * *}$ \\
\hline Number of seeds/pod & $-0.26^{* *}$ & -0.15 & 0.04 \\
\hline Thousand seeds' weight (TSW) & $-0.21^{*}$ & $-0.47^{* * *}$ & $0.52^{* *}$ \\
\hline Seed yield/plant (SY/P) & $-0.18^{*}$ & $-0.45^{* * *}$ & $0.35^{* * *}$ \\
\hline Seed total glucosinolates content (GLS) & - & 0.07 & $0.32^{* * *}$ \\
\hline Seed sinigrin content (SIN) & - & - & $-0.92^{* * *}$ \\
\hline
\end{tabular}

$*, * *$, and $* * *$ : significance at $0.05,0.01$, and 0.001 probability level, respectively.

twice the time for seed filling compared to others. The same trend was reported for plant height (Table 2) where the tallest genotypes were twice as high as the shortest ones. The most marked differences were noticed for TSW: number of seeds per pod and SY/P for which contrasting genotypes differed by nearly $450 \%, 500 \%$, and $600 \%$, respectively, between extreme accessions.

Correlation analysis showed that both total glucosinolates and GNA were positively related to both SFD and TSW (Table 3). Moreover GNA is correlated positively to SY/P and negatively to plant height and SIN. This latter trait is associated negatively with TSW, SY/P, and SFD and positively with plant height. A positive correlation was observed between SY/P and TSW $\left(r=0.37^{* * *}\right)$.

\section{Discussion}

Large genotypic variability was observed within the studied collection for all measured traits. The observed values for total glucosinolates were similar to those observed by Lionneton et al. [21] within a mapping doubled haploid population. The concentration range of glucosinolates observed in our study was largely higher than those reported in other studies for glucosinolate content in mustard seeds [22-25]. However, most of those studies focused on varieties devoted to oil and meal production and thus with low glucosinolate contents $[14,15,17,18]$.

Detailed analysis of these glucosinolates showed large genotypic differences for both sinigrin and gluconapin levels in our collection. As previously reported SIN was consistently dominant over GNA $[10,19,20]$.

The relationships observed between SFD and total glucosinolates, GNA, and SIN mirrored the fact that genotypes which have longer seed filling duration are richer in glucosinolates, and in GNA and are poorer in SIN. In the same way, heavy seeds seem poorer in SIN according to the negative correlation observed between TSW and SIN. This suggests that SIN accumulation in the seeds could occur in the early phase of maturation and then stop whatever the seed growth and the duration of seed filling are as proposed by biosynthesis pathway of both glucosinolates (Figure 2). Conversely GNA could accumulate in a later phase of seed growth taking profit from the long maturation. Moreover, for genotypes richest in GNA, SIN serves as precursor for GNA synthesis (Figure 2). This balance could explain the absence of a significant relationship between total glucosinolate and SIN content. On the other hand, tall plants are richer in SIN and poorer in GNA. These interesting correlations were not approached in other works and the biological explanations of these correlations need further investigations. However, we can assume that the association between plant height and seed SIN resulted from the positive relationship between vegetative biomass (not measured here) and plant height noticed in other studies $[24,25]$. Previous reports showed that seed SIN is positively related to green tissue SIN level $[19,20$, 23-26] suggesting that a part of seed sinigrin was provided by translocation from green tissues. This is confirmed by the detailed study of Zukalová et al. [20], showing that, during growth, SIN decreases in the vegetative parts of the plant while it increases in the generative ones. According to these authors, this result proves unambiguously that pod SIN is transported into seeds. One can then assume that transport of SIN from the green parts to the pods and then to the seeds can continue as long as these organs are alive and progressively stop when they senesce. SIN accumulation would then decrease when the leaves turn yellow and stop when they fall. Conversely, GNA would continue to accumulate, after leaf fall, by using a different process [18].

Broad genotypic differences were also observed for agronomical traits. Similar values were reported in Chinese and Indian brown mustard collections [14]. These authors also showed that TSW is the most important yield component. Our study also pointed out the role of TSW since the correlation with yield is significantly positive. Other works have reported similar associations between yield and yield components [10, 24, 25].

\section{Conclusion}

Our results provide evidence for large genotypic variability within the studied brown mustard collection mostly for glucosinolates and sinigrin levels in seeds. These results are of interest for industrial uses. Indeed, breeders need to combine agronomic and nutritional traits in the same genotypes. Some intriguing correlations between different glucosinolates and agronomic traits need to be more thoroughly investigated. Moreover, relationships between glucosinolates profiles in seed and different green organs would help to increase our 


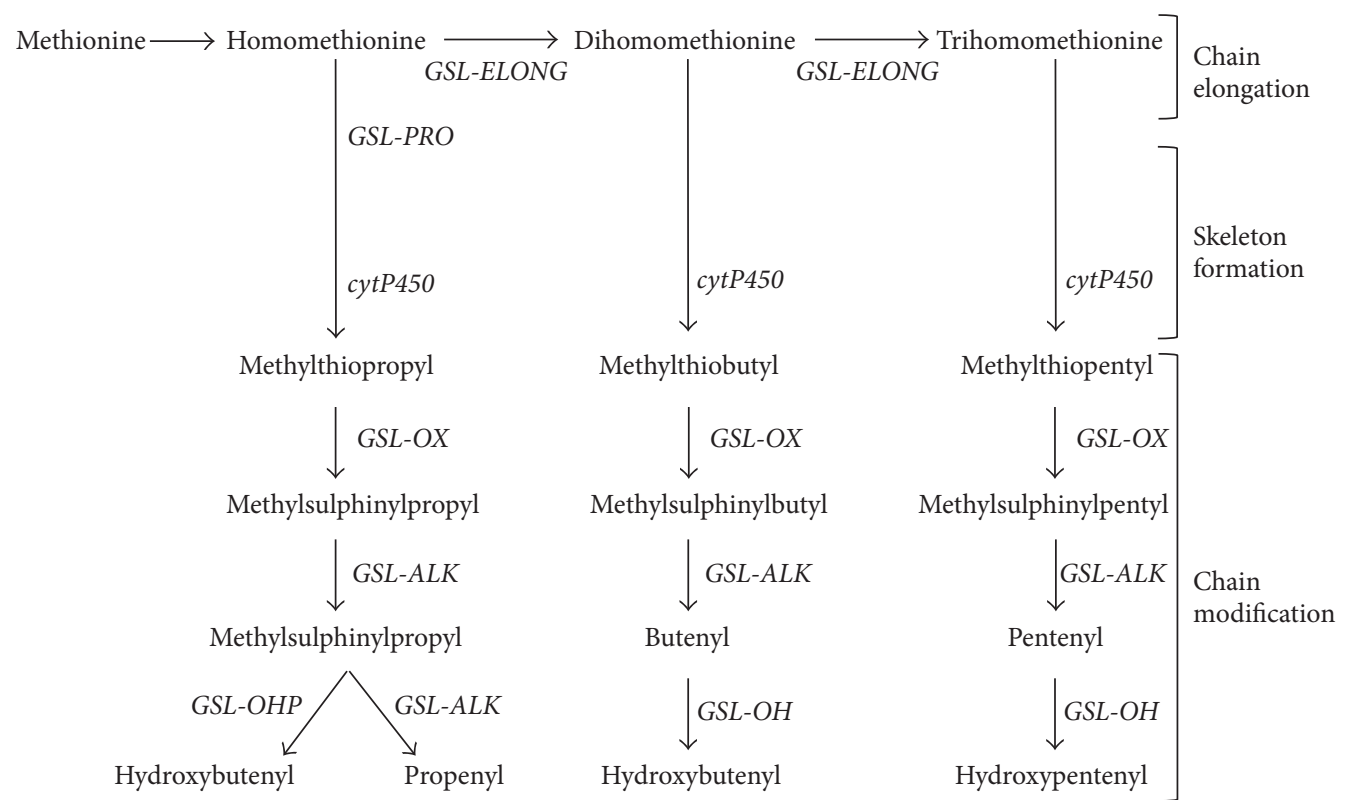

FIGURE 2: Simplified model of the biosynthesis pathway of aliphatic glucosinolate in Brassica [19, 20].

knowledge and would help our understanding of the biological relationships between these traits. Moreover, industrial production requires seeds with high sinigrin content $(80-$ $100 \mu \mathrm{mol} \cdot \mathrm{g}^{-1}$ ) and high seed yield. This objective could be easily achieved by combining both traits in new selected genotypes. Some studied genotypes showed high levels of glucosinolates and SIN and could be used for mustard condiment or for experiments or to be introduced in breeding programs for improvement of glucosinolates level in general and SIN content in particular.

\section{Conflict of Interests}

The author declares that there is no conflict of interests regarding the publication of this paper.

\section{Acknowledgment}

The author is grateful to Thierry Guinet for technical help during experimentation.

\section{References}

[1] M. Björkman, I. Klingen, A. N. E. Birch et al., "Phytochemicals of Brassicaceae in plant protection and human healthinfluences of climate, environment and agronomic practice," Phytochemistry, vol. 72, no. 7, pp. 538-556, 2011.

[2] B. Abbaoui, K. M. Riedl, R. A. Ralston et al., "Inhibition of bladder cancer by broccoli isothiocyanates sulforaphane and erucin: characterization, metabolism, and interconversion," Molecular Nutrition and Food Research, vol. 56, no. 11, pp. 16751687, 2012.

[3] N. H. Kadir, J. T. Rossiter, and N. J. Gooderham, "The chemopreventive properties of cruciferous vegetables: is oxidative stress in cancer cell cytotoxicity induced by glucosinolate hydrolysis products?" Toxicology, vol. 290, no. 2-3, pp. 118-119, 2011.
[4] K. Sakao, S. Desineni, E.-R. Hahm, and S. V. Singh, "Phenethyl isothiocyanate suppresses inhibitor of apoptosis family protein expression in prostate cancer cells in culture and in vivo," The Prostate, vol. 72, no. 10, pp. 1104-1116, 2012.

[5] E. Peñas, R. I. Limón, C. Vidal-Valverde, and J. Frias, "Effect of storage on the content of indole-glucosinolate breakdown products and vitamin $\mathrm{C}$ of sauerkrauts treated by high hydrostatic pressure," LWT_Food Science and Technology, vol. 53, no. 1, pp. 285-289, 2013.

[6] Z.-Y. Li, Y. Wang, W.-T. Shen, and P. Zhou, "Content determination of benzyl glucosinolate and anti-cancer activity of its hydrolysis product in Carica papaya L.," Asian Pacific Journal of Tropical Medicine, vol. 5, no. 3, pp. 231-233, 2012.

[7] Z. Zhao, W. Zhang, B. A. Stanley, and S. M. Assmann, "Functional proteomics of Arabidopsis thaliana guard cells uncovers new stomatal signaling pathways," The Plant Cell, vol. 20, no. 12, pp. 3210-3226, 2008.

[8] P. Bednarek, M. Piślewska-Bednarek, A. Svatoš et al., "A glucosinolate metabolism pathway in living plant cells mediates broadspectrum antifungal defense," Science, vol. 323, no. 5910, pp. 101106, 2009.

[9] N. K. Clay, A. M. Adio, C. Denoux, G. Jander, and F. M. Ausubel, "Glucosinolate metabolites required for an Arabidopsis innate immune response," Science, vol. 323, no. 5910, pp. 95-101, 2009.

[10] E. Lionneton, G. Aubert, S. Ochatt, and O. Merah, "Genetic analysis of agronomic and quality traits in mustard (Brassica juncea)," Theoretical and Applied Genetics, vol. 109, no. 4, pp. 792-799, 2004.

[11] M. Handiseni, J. Brown, R. Zemetra, and M. Mazzola, "Effect of Brassicaceae seed meals with different glucosinolate profiles on Rhizoctonia root rot in wheat," Crop Protection, vol. 48, pp. 1-5, 2013.

[12] L. C. Ascencion, W. Liang, and T. Yen, "Control of Rhizoctonia solani damping-off disease after soil amendment with dry tissues of Brassica results from increase in Actinomycetes population," Biological Control, vol. 82, pp. 21-30, 2015. 
[13] L. Bell, M. J. Oruna-Concha, and C. Wagstaff, "Identification and quantification of glucosinolate and flavonol compounds in rocket salad (Eruca sativa, Eruca vesicaria and Diplotaxis tenuifolia) by LC-MS: highlighting the potential for improving nutritional value of rocket crops," Food Chemistry, vol. 172, pp. 852-861, 2015.

[14] J. S. Chauhan, M. K. Tyagi, S. Kumar, P. Tyagi, N. B. Singh, and S. K. Yadav, "Development, selection and characterization of low erucic acid, low glucosinolates lines in Indian mustard (Brassica juncea L.)," in Proceedings of the 11th International Rapeseed Congress, 2002.

[15] Y. S. Sodhi, A. Mukhopadhyay, N. Arumugam et al., "Genetic analysis of total glucosinolate in crosses involving a high glucosinolate Indian variety and a low glucosinolate line of Brassica juncea," Plant Breeding, vol. 121, no. 6, pp. 508-511, 2002.

[16] R. Augustine, A. Mukhopadhyay, and N. C. Bisht, "Targeted silencing of BjMYB28 transcription factor gene directs development of low glucosinolate lines in oilseed Brassica juncea," Plant Biotechnology Journal, vol. 11, no. 7, pp. 855-866, 2013.

[17] A. Agnihotri and N. Kaushik, "Towards nutritional quality improvement in Indian mustard (Brassica juncea [L.]. Czern and Cross) var. Pusa Bold," in Proceedings of the 11th International Rapeseed Congress, pp. 501-503, Copenhagen, Denmark, July 2003.

[18] V. Beniwal, H. Aggarwal, A. Kumar, and V. Chhokar, "Lipid content and fatty acid change in the developing silique wall of mustard (Brassica juncea L.)," Biocatalysis and Agricultural Biotechnology, vol. 4, no. 1, pp. 122-125, 2015.

[19] N. Rangkadilok, M. E. Nicolas, R. N. Bennett, R. R. Premier, D. R. Eagling, and P. W. J. Taylor, "Developmental changes of sinigrin and glucoraphanin in three Brassica species (Brassica nigra, Brassica juncea and Brassica oleracea var. italica)," Scientia Horticulturae, vol. 96, no. 1-4, pp. 11-26, 2002.

[20] H. Zukalová, J. Vašák, D. Nerad, and P. Štranc, “The role of glucosinolates of Brassica genus in the crop system," Rostlinna Vyroba, vol. 48, no. 4, pp. 181-189, 2002.

[21] E. Lionneton, G. Aubert, S. Ochatt, and O. Merah, "Candidate gene approach and QTL mapping identified loci involved in glucosinolate biosynthesis in brown mustard," Agroindustria, vol. 3, no. 1, pp. 343-345, 2004.

[22] F. C. Ogbonnaya, G. Halloran, E. Pang, and N. Gororo, "Molecular analysis of genetic diversity in Brassica juncea and B. nigra germplasm accessions," in Proceedings of the 11th International Rapeseed Congress, pp. 489-491, Copenhagen, Denmark, July 2003.

[23] K. Juerges and W. Thies, "Quantitative analysis of the indole glucosinolates content in seeds and leaves of Brassica napus and Brassica campestris," Zeitschrift für Pflanzenzüchtung, vol. 84, pp. $168-178,1980$.

[24] K. Das, P. K. Barua, and G. N. Hazarika, "Genetic variability and correlation in Indian mustard," Journal of the Agricultural Science Society of North-East India, vol. 11, pp. 262-264, 1998.

[25] H. R. Mahla, S. J. Jambhulkar, D. K. Yadav, and R. Sharma, "Genetic variability, correlation and path analysis in Indian mustard [(Brassica juncea (L.)]," Indian Journal of Genetics and Plant Breeding, vol. 63, pp. 171-172, 2003.

[26] Y. J. Xu, L. Zhu, M. G. Sun, M. Z. Gian, and F. R. Chen, "Glucosinolate content of the rape plant and organs in various growing periods and its early prediction," Acta Agronomica Sinica, vol. 9, pp. 107-116, 1983. 

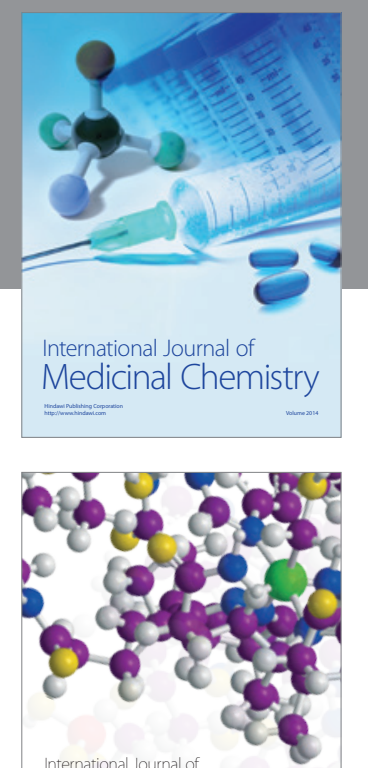

\section{Carbohydrate} Chemistry

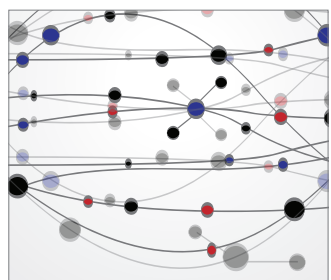

The Scientific World Journal
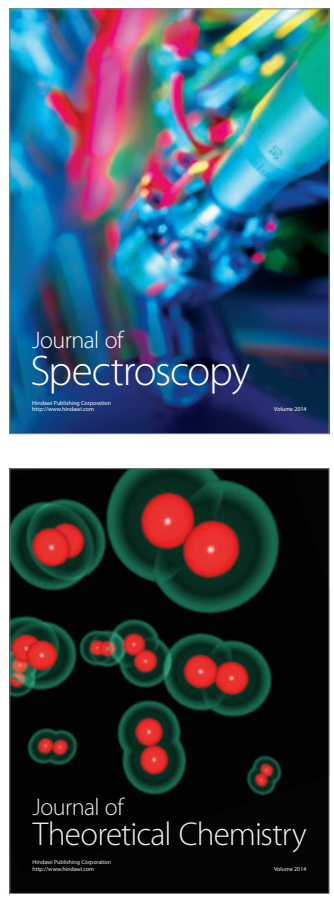
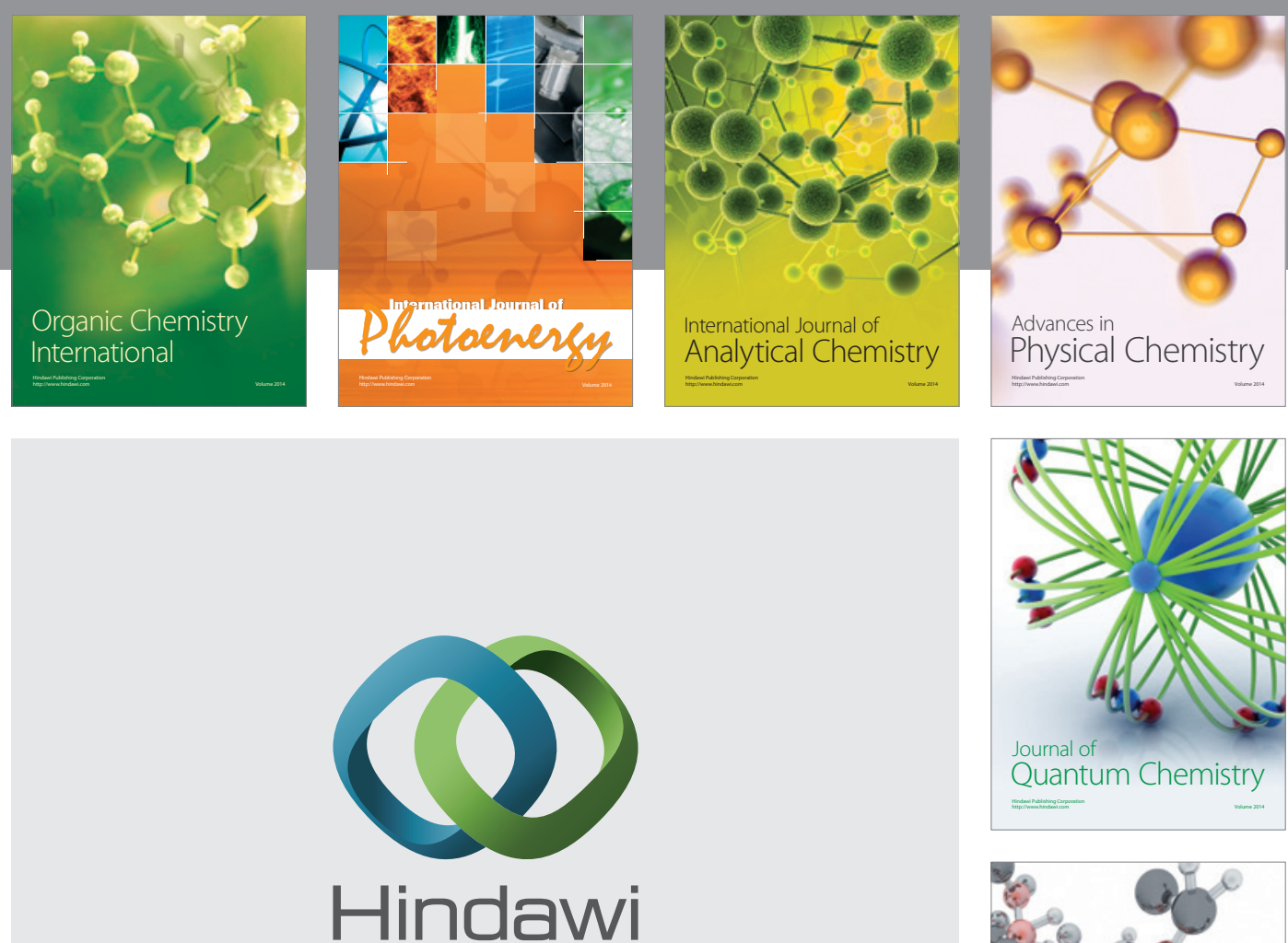

Submit your manuscripts at

http://www.hindawi.com

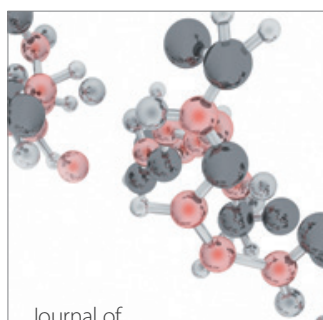

Analytical Methods

in Chemistry

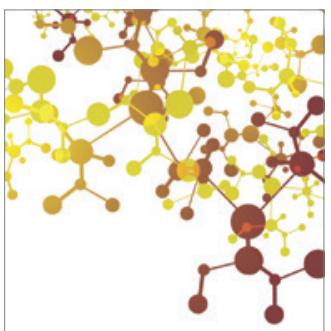

Journal of

Applied Chemistry

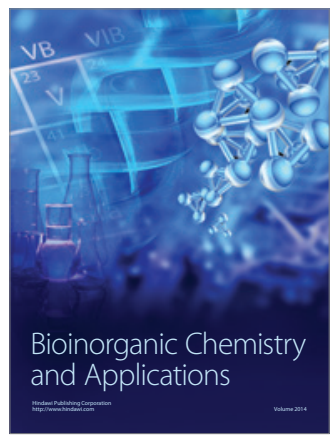

Inorganic Chemistry
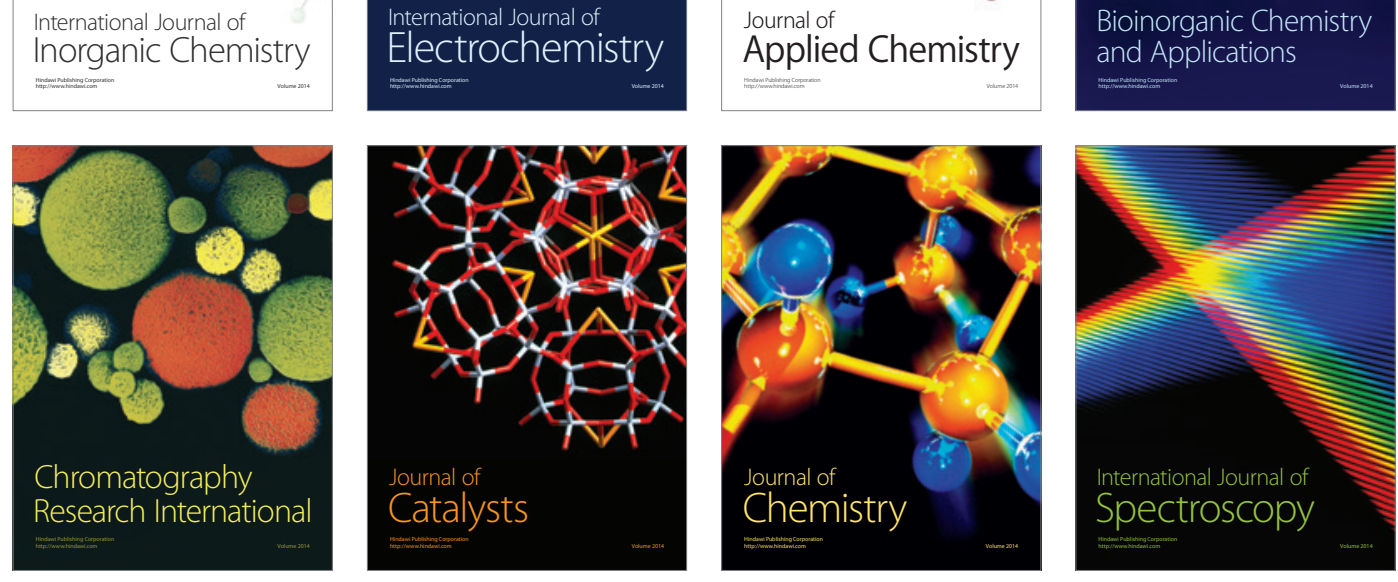